\title{
Genetic control of renal tumorigenesis by the mouse Rtm1 locus
}

\author{
José Ricardo Jensen ${ }^{1 \dagger}$, Antonella Galvan ${ }^{2 \dagger}$, Andrea Borrego ${ }^{1}$, Wafa Hanna Koury Cabrera', Orlando Garcia Ribeiro ${ }^{1}$, \\ Nancy Starobinas ${ }^{1}$, Marcelo De Franco ${ }^{1}$, Maurizio Colecchia ${ }^{3}$, Alessia Bertolotti ${ }^{3}$, Tommaso Antonio Dragani ${ }^{2}$ \\ and Olga Célia Martinez Ibañez ${ }^{1 *}$
}

\begin{abstract}
Background: The genetic basis of susceptibility to renal tumorigenesis has not yet been established in mouse strains. Mouse lines derived by bidirectional phenotypic selection on the basis of their maximal (AIRmax) or minimal (AIRmin) acute inflammatory responsiveness differ widely in susceptibility to spontaneous and urethane-induced renal tumorigenesis. To map the functional loci modulating renal tumor susceptibility in these mice, we carried out a genome-wide genetic linkage study, using SNP arrays, in an (AlRmax $x$ AIRmin)F2 intercross population treated with a single urethane dose at 1 week of age and phenotyped for renal tumors at 35 weeks of age.

Results: AIRmax mice did not develop renal tumors spontaneously nor in response to urethane, whereas in AIRmin mice renal tumors formed spontaneously (in 52\% of animals) and after urethane induction (89\%). The tumors had a papillary morphology and were positive for alpha-methylacyl-CoA racemase and negative for CD10. By analysis of 879 informative SNPs in 662 mice, we mapped a single quantitative trait locus modulating the incidence of renal tumors in the (AIRmax x AIRmin)F2 intercross population. This locus, which we named Renal tumor modifier QTL 1 (Rtm1), mapped to chromosome 17 at $23.4 \mathrm{Mb}$ (LOD score $=15.8$ ), with SNPs rs3696835 and rs3719497 flanking the LOD score peak. The A allele of rs3719497 from AIRmin mice was associated with a 2.5 -fold increased odds ratio for renal tumor development. The LOD score peak included the Tuberous sclerosis 2 (Tsc2) gene which has already been implicated in kidney disease: loss of function by germline retroviral insertion is associated with spontaneous renal tumorigenesis in the Eker rat, and heterozygous-null $\mathrm{Tsc}_{\mathrm{C}}{ }^{(+-)}$mice develop renal cystadenomas.
\end{abstract}

Conclusions: We mapped Rtm 1 as a single major locus modulating renal tumorigenesis in a murine intercross population. Thus, the AIR mouse lines can be considered a new genetic model for studying the role of germline and somatic molecular alterations in kidney neoplastic disease.

Keywords: Animal models, Genetic linkage, Inflammation, Kidney cancer, QTL, SNPS

\section{Background}

In humans, kidney cancer is a complex disease comprising several different tumor types characterized by different somatic mutations and showing different histological features and clinical courses [1]. Risk factors include smoking, obesity and hypertension [2]. Genetic factors also underlie the predisposition to renal cancers, as familial aggregations have been reported and the risk of developing the disease for first-degree relatives of

\footnotetext{
* Correspondence: olga.ibanez@butantan.gov.br

'Equal contributors

'Laboratory of Immunogenetics, Instituto Butantan, Avenida Dr. Vital Brazil, 1500, 05503-900 São Paulo, Brazil

Full list of author information is available at the end of the article
}

renal cancer patients is 1.7 - to 2.6 -fold higher than that of the general population [3]. Studies of families with hereditary kidney cancers have permitted the identification of mutations in several genes, including the TSC1 and TSC2 genes linked with tuberous sclerosis, a multi-system hamartoma syndrome (reviewed in [1]). In addition, genome-wide association analyses in large case-control studies have detected three loci, on chromosomes 2p21, 11q13.3, and 12p11.23 [4,5], associated with an increased risk of renal cell carcinoma (RCC), the most common renal cancer in humans. Despite this progress, there is still much to unravel about the genetic susceptibility to this heterogeneous disease; the ability to study the

\section{Biomed Central}

(c) 2013 Jensen et al.; licensee BioMed Central Ltd. This is an open access article distributed under the terms of the Creative Commons Attribution License (http://creativecommons.org/licenses/by/2.0), which permits unrestricted use, distribution, and reproduction in any medium, provided the original work is properly cited. 
genetics of renal cancer in a mouse model would therefore prove advantageous.

Until now, a mouse model suitable for studying the genetics of the inherited predisposition to renal tumor has not been described but, as we show here, does already exist. We previously developed the AIRmax and AIRmin mouse lines by phenotypically selecting, from a heterogeneous population, mice that had either an intense or a weak acute inflammatory response (AIR) [6]. The phenotypes used to select these strains were the number of infiltrated leukocytes and the protein content at the site of inflammation induced by the subcutaneous injection of a non-specific, non-immunogenic agent (polyacrylamide beads) [6]. After about 20 generations of selective breeding, AIRmax and AIRmin mouse lines presented extreme "maximal" and "minimum" phenotypes, respectively [7] and, at that limit, were considered to be homozygous for the quantitative trait loci (QTL) that control the acute inflammatory reaction. In addition to the inflammatory response, AIRmax and AIRmin mice differ in their susceptibility to several types of chemically induced tumors, in particular in the lung, skin and colon [8-10]. For example, adult AIRmax mice are resistant and AIRmin are susceptible to developing lung tumors in response to urethane [9], a multiorgan carcinogen with a short half-life $(<1 \mathrm{~h})$ [11]. Although the susceptibility of these mice to kidney tumors has not yet been studied, we were motivated to investigate their suitability as a model system for studying renal cancer genetics, especially because in humans the inflammatory response seems to play a role in the prognosis of renal cancer patients [12].

In the present study, a single dose of urethane injected in 7-day old mice induced, in addition to lung tumors, multiple renal tumors in AIRmin mice but not in AIRmax mice. The genetic basis for the different susceptibility of the two lines was investigated by genome-wide SNP genotyping followed by linkage analysis with renal tumor incidence in the pedigree of a large (AIRmax X AIRmin)F2 intercross population.

\section{Results}

Renal tumorigenesis in AIRmax and AIRmin mice and in interline crosses

Untreated AIRmax mice $(n=15)$, when analyzed at 57 weeks of age, had no renal tumors, whereas 11 (52\%) of 21 untreated AIRmin mice had spontaneous renal tumors at the same age. When mice pups were treated with urethane at 7 days and followed until 35 weeks of age, AIRmax mice remained resistant to renal tumorigenesis and did not develop any gross kidney tumor (Figure 1). In contrast, 8 (89\%) of 9 urethane-treated AIRmin mice developed such tumors. Susceptibility to renal tumorigenesis was inherited as a co-dominant trait, since the incidence of renal tumors in urethane-treated (AIRmax $\mathrm{x}$ AIRmin)

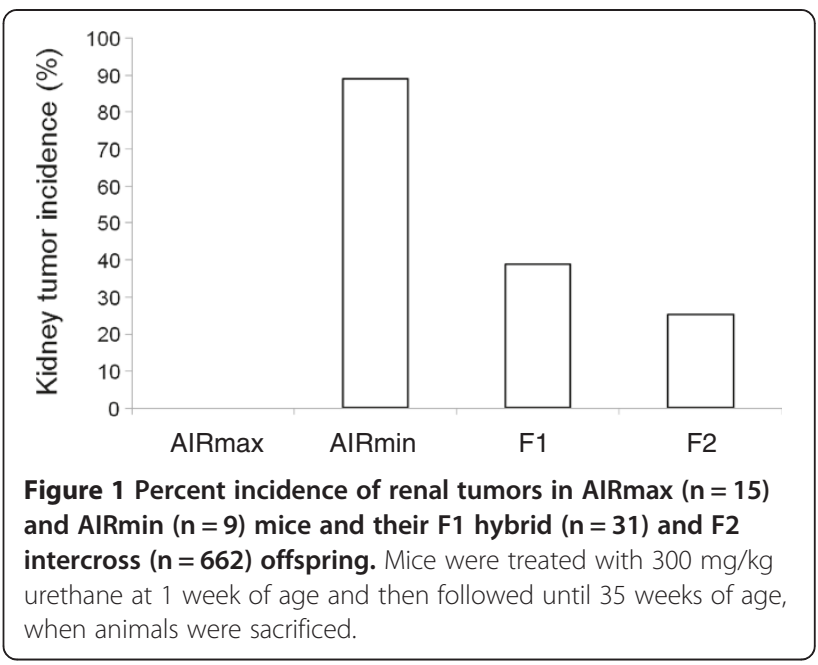

F1 mice was 39\% while that in the (AIRmax x AIRmin)F2 intercross population was $25 \%$. No statistically significant difference was observed in renal tumor incidence between male and female mice in any line.

Tumor-bearing mice usually had multiple kidney tumors, which varied in size as seen both at gross examination and microscopically. Histopathological analysis of kidney tumors in selected F2 mice revealed the occurrence of lesions suggestive of papillary renal cell tumors, characterized by malignant epithelial cells constituting papillae and lining tubules (Figure 2A). Tumor-lined cysts with papillary excrescences were also seen (Figure 2B). Immunohistochemical analysis showed diffuse, marked staining for alpha-methylacyl-CoA racemase (AMACR) (Figure 2C), which in humans is a sensitive marker for papillary renal neoplasms. Staining for CD10, which is a marker of clear cell RCC and which is less frequently expressed by papillary tumors, was negative in our model (Figure 2D).

In addition, we carried out real-time PCR on RNA extracted from renal tumors and normal kidney tissue to measure the mRNA levels of known markers of these tumors. This analysis showed that the vimentin and $\beta 2$-microglobulin genes were upregulated in renal tumors of F2 mice $(n=12)$ compared to normal renal tissue (not shown).

\section{One major locus controls renal tumor susceptibility in AIR mice}

Of the 693 (AIRmax x AIRmin)F2 intercross mice available, genomic DNA and renal tumor phenotype were available for 662 animals. These mice were genotyped using SNP arrays representing a panel of 1449 SNPs. After quality control filtering of the genotype data, 879 markers (824 autosomal) resulted informative and were used in genome-wide linkage analysis. A statistical threshold for linkage with renal tumor incidence was determined by 


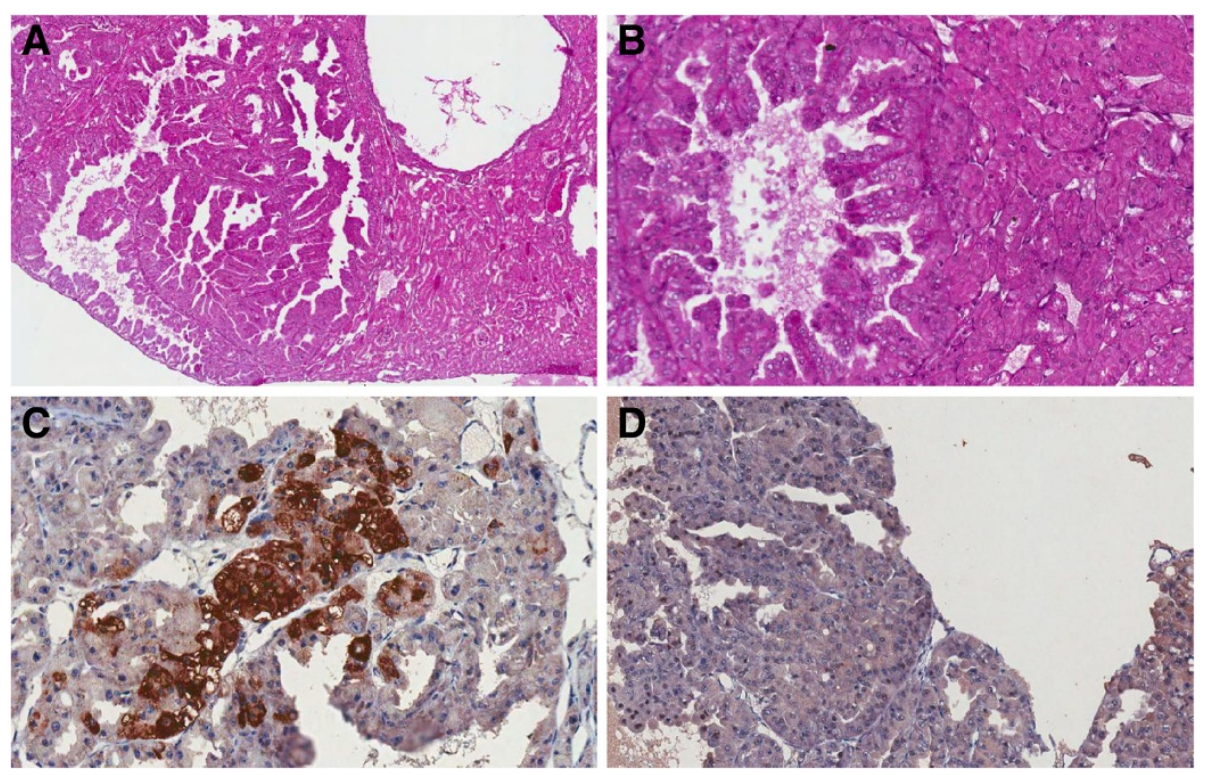

Figure 2 Histological section of a papillary neoplastic proliferation of a kidney from an (AIRmax x AIRmin)F2 mouse. Panel A, hematoxylin and eosin stained section, 40X magnification. Panel B, same section at 250X magnification. The renal tumor resulted positive for racemase (AMACR) immunostaining (panel C, 250X magnification) and negative for CD10 immunostaining (panel D, 250X magnification).

permutation analysis, resulting in a logarithm of odds (LOD) score of 3.7, for $\alpha=0.05$ genome-wide statistical probabilities (10,000 permutations).

Genome-wide linkage analysis detected a single QTL on chromosome 17, with a peak LOD score of 15.8, at 23.4 Mb (Figure 3A). The 1-LOD support interval was $11 \mathrm{Mb}$ long, ranging from 18 to $29 \mathrm{Mb}$ (Figure 3B). The SNPs flanking the LOD score peak were rs3696835 (22.681 Mb) and rs3719497 (25.502 Mb). We designated this locus Renal tumor modifier QTL 1 (Rtm1) associated with the incidence of renal tumors induced by urethane treatment. No other region of the genome showed a significant or suggestive association with the phenotype. Therefore, the Rtm1 QTL likely harbors one or more genes with major effects in renal tumorigenesis.

Association analysis showed that, at SNP rs3719497, the $G$ allele inherited from AIRmax mice confers resistance whereas the A allele from parental AIRmin was associated with a 2.5-fold increase in odds ratio (OR) for renal tumor development $\left(\mathrm{P}=1.1 \times 10^{-12}\right.$, per allele $\mathrm{OR}=2.5 ; 95 \%$ CI, 1.9 to 3.2). The ORs associated at each genotype in F2 mice showed a very strong association of homozygosity or heterozygosity of the AIRmin-derived A allele with renal tumor incidence (Figure 4). Homozygous inheritance of the AIRmin-derived allele at this locus caused a $\sim 16-$ fold increase in the incidence of renal tumors (from $2.5 \%$ in heterozygotes to $30.5 \%$ ). Similar findings were observed at the rs3696835, with the AIRmin-derived allele associated with an increased risk of renal tumors (not shown).
In the 1-LOD interval of the Rtm 1 locus, between 18 and $29 \mathrm{Mb}, 378$ known or predicted genes map ${ }^{\mathrm{a}}$. Among these genes, the $T s c 2$ gene, located within the LOD score peak, at 24.596-24.633 Mb, seems particularly relevant, due to its known involvement in renal tumorigenesis in rats, humans and genetically modified mice.

Genotypes of the 662 F2 mice were also assessed for association with the inflammatory response measured by the number of infiltrating cells (Ncell) at the local exudates induced by a subcutaneous injection of Bio-Gel P-100. The LOD score thresholds for linkage of Ncell, determined by permutation analysis, were 3.34 and 3.64, respectively, for $\alpha=0.1$ and $\alpha=0.05$ genome-wide statistical probabilities (5000 permutations). On chromosome 17, which contains the Rtm1 locus, no loci had LOD scores above the genome-wide thresholds (not shown). This result indicates that Rtm1 is independent of any loci associated with the inflammatory response.

\section{Discussion}

Our findings show that AIRmin mice carry a co-dominant genetic susceptibility trait to renal tumorigenesis induced by urethane. By genome-wide linkage mapping of an (AIRmax x AIRmin)F2 intercross population, we found that such trait is regulated by germline genetic variations in a locus in the proximal region of chromosome 17. Within this locus, which we named Rtm1, the A allele of rs3719497 was associated with a 2.5-fold increase in OR for renal tumor development; homozygous inheritance of this allele from AIRmin mice increased the incidence of 

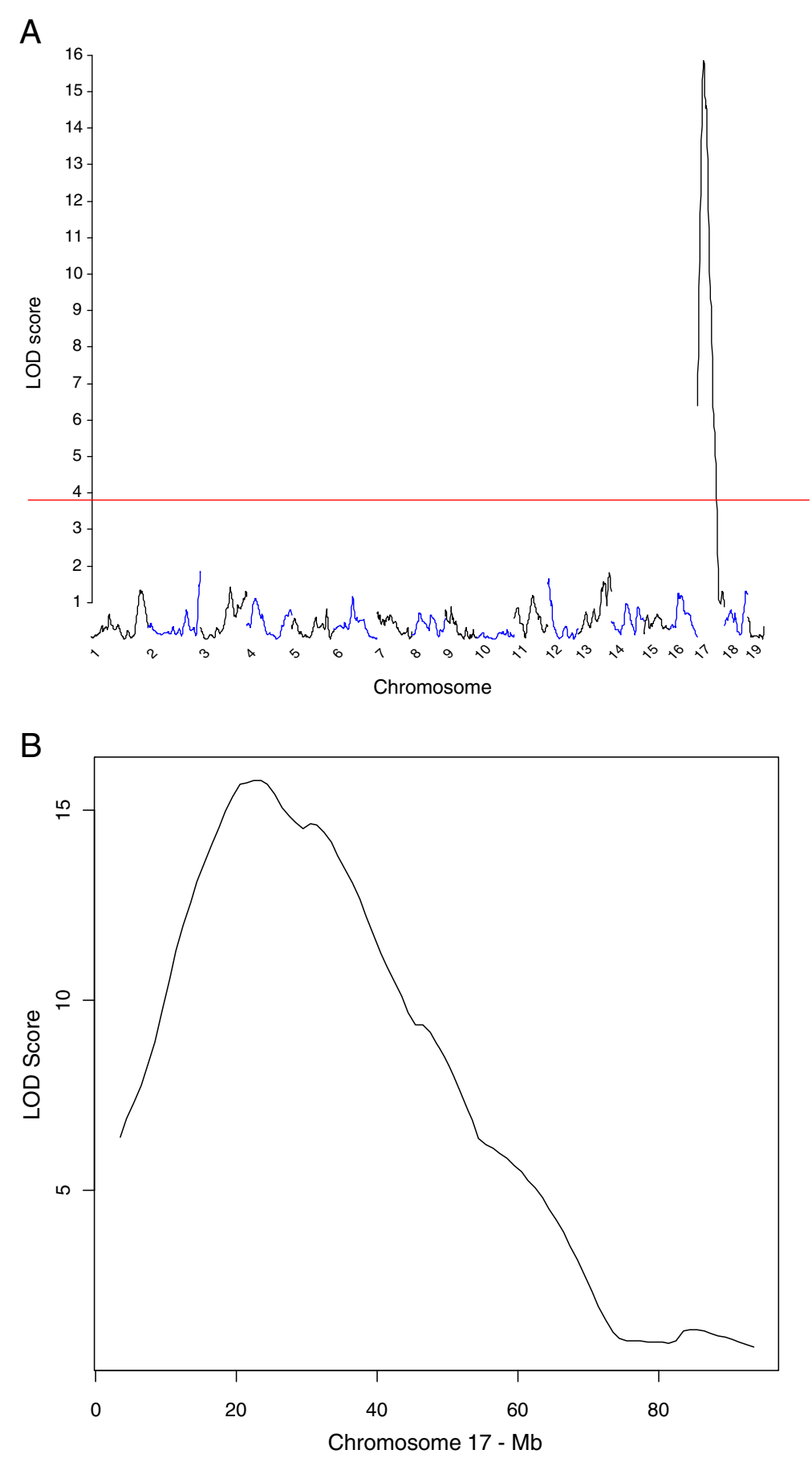

Figure 3 Genome-wide genetic linkage analysis of renal tumor susceptibility in 662 (AIRmax x AIRmin)F2 intercross mice. Panel A,

above the genome-wide threshold value of $L O D$ score $=3.67$ for $a=0.05$ (horizontal red line), a single locus on chromosome 17 was detected. Panel $\mathbf{B}$, details of chromosome 17 showing the mapping of the Rtm 1 locus, with LOD score peak of 15.8, at $23.4 \mathrm{Mb}$ distance from the centromere.

renal tumors by $\sim 16$-fold. The Rtm1 locus is novel and unique, as no other loci modulating renal tumorigenesis have previously been mapped in mouse crosses.

No significant linkage was found between the inflammatory response and SNPs on chromosome 17. This finding indicates that the Rtm1 locus was fixed during phenotypic selection of AIR mice, independently from loci modulating inflammatory response phenotypes. Such a phenomenon may be due to random genetic drift, as already proposed for skin tumorigenesis in selected mouse lines [13]. 


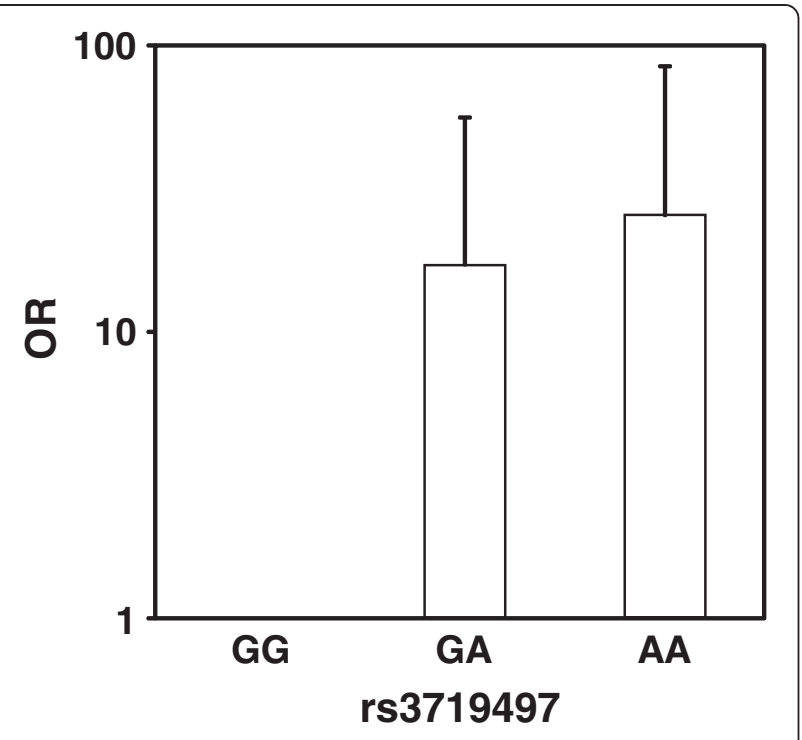

Figure 4 Odds ratios (ORs) of renal tumor incidence of (AIRmax x AIRmin)F2 mice by genotype at rs3719497 on chromosome 17, located near the peak LOD score of genetic linkage between renal tumor incidence and genomic variants. At the reference genotype $\mathrm{GG}$, carried by AIRmax mice, renal tumors were observed in 4 of $163 \mathrm{~F} 2$ mice (2.5\% incidence, reference category). At the GA genotype, renal tumors were seen in 110 of 361 mice (30.5\%; OR=14.4; 95\% Cl, 6.0 - 56.6), while at the AA genotype renal tumors were observed in 54 of 138 mice $(39.1 \%$; OR $=25.5 ; 95 \%$ $\mathrm{Cl}, 8.5-86.1)$. ORs and $95 \% \mathrm{Cls}$ are reported on a logarithmic scale.

AIRmax and AIRmin mice are known to differ in susceptibility to chemically induced tumors [8-10], and here we show that they also differ in susceptibility to spontaneous tumors: in the absence of any carcinogenic treatment, $>50 \%$ of AIRmin mice developed renal tumors at 57 weeks of age, whereas no AIRmax mouse did. Although we did not carry out a time-course analysis of spontaneous renal tumor incidence, we noticed that after urethane treatment of 1-week-old AIRmin mice, renal tumors were observed earlier (34 weeks after treatment) and with an increased incidence ( $90 \%)$ as compared to spontaneous renal tumorigenesis in the same mouse line. In contrast, urethane treatment did not induce renal tumors in the genetically resistant AIRmax mice. Therefore, it seems that a correlation exists between strain susceptibility to spontaneous and urethane-induced renal tumorigenesis, as has already been observed for lung tumorigenesis in a meta-analysis of numerous inbred mouse strains [14]. Our results suggest that both spontaneous and urethaneinduced renal tumors are controlled by the same genetic locus, i.e., Rtm1, although we cannot exclude that additional loci may control spontaneous renal tumor susceptibility in AIR mice.

Characterization of the renal tumors by immunohistochemistry showed the expression of AMACR, a peroxisomal and mitochondrial enzyme involved in the $\beta$-oxidation of branched-chain fatty acids and fatty acid derivatives. The AMACR gene has one of the highest expression levels in papillary RCC in humans [15]. The presence of CD10 (common acute lymphoblastic leukemia antigen or neprilysin), on the other hand, was not detected. This protein is a cell membrane neutral endopeptidase which participates in the post-secretory inactivation of inflammatory and vasoactive peptides [16]. In the diagnosis of renal tumors, CD10 is more often positive in clear cell RCC than in papillary RCC [17]. Real-time PCR pointed to the overexpression of vimentin and $\beta 2$-microglobulin. Vimentin protein positivity has been reported in both clear cell and papillary RCCs in human samples [18], and $\beta 2$-microglobulin overexpression has been detected in human RCC [19].

Spontaneous renal tumors are rare in inbred mouse strains $[20,21]$. One exception is the $\mathrm{BALB} / \mathrm{c}$ substrain $\mathrm{BALB} / \mathrm{cf} / \mathrm{Cd}$, which has a $24 \%-70 \%$ incidence of kidney adenocarcinomas [22,23], probably due to the insertion of the mouse mammary tumor virus into a not yet identified chromosomal domain that is implicated in kidney tumorigenesis [23]. Gene disruption is also known to cause spontaneous renal carcinoma in the Eker rat, where an endogenous retroviral element (the rat intracisternal A-particle) has integrated into an intron of the tumor suppressor gene tuberous sclerosis 2 (Tsc2) [24-26]. This intronic transposition leads to the production of aberrant $T s c 2$ transcripts, causing a functional inactivation of the $T s c 2$ gene which leads to renal tumorigenesis.

The murine Tsc2 gene on chromosome 17 maps to the Rtm1 locus peak identified in this study. This gene spans over $36.7 \mathrm{~kb}$, contains 40 exons, generates a full length transcript of $6018 \mathrm{bp}$ and encodes a protein of 1742 amino acids ${ }^{\mathrm{b}}$. The protein, called tuberin or TSC2 (in humans), controls the mTOR (mammalian target of rapamycin) signaling pathway [27]. Of the 1150 known polymorphisms in this gene among inbred strains ${ }^{c}$; four are missense variants in exons whereas the others are found in introns or in the upstream or downstream regions where they might play a role in modulating transcript levels. The gene's genomic location and involvement in renal tumorigenesis in the rat make $T s c 2$ a good candidate for the AIR renal tumor locus. Interestingly, $T s c 2^{(+/-)}$mice develop renal cystadenomas [28]. Sequencing the $T_{s c} 2$ gene in AIRmax and AIRmin mice, as well as in mice of their F2 intercross, may reveal polymorphisms that, by influencing $T s c 2$ expression or tuberin function, modulate the susceptibility of these mice to renal tumorigenesis.

Another candidate gene that maps close to $T s c 2$ is the Pkd1 gene, which encodes the transmembrane protein polycystin-1. Mutations leading to a loss of function at this gene cause autosomal dominant polycystic kidney disease in both humans [29] and mouse models [30]. Polycystin-1 is involved in cell adhesion and has been 
shown to inhibit cancer cell migration and invasion, leading to the suggestion that $P d k 1$ is a tumor suppressor gene [31]. There is also a functional link between Tsc 2 and Pkd1: in human cells, TSC2 protein alternates from an inactive, phosphorylated form in the cytosol to an active, non-phosphorylated form at the plasma membrane bound to the intracellular, carboxy-terminal tail of polycystin-1; in this subcellular position, TSC2 protein activates the GTPase of Rheb, resulting in the inactivation of the mTOR pathway [27].

\section{Conclusions}

Herein, we mapped Rtm1 as a novel mouse modifier locus of chemically induced renal tumorigenesis in pedigrees of non-inbred mice. This locus spans the $T s c 2-P k d 1$ region of chromosome 17, whose candidate genes are involved in renal cancer in animal models and humans. These results point to the possible involvement of polymorphisms in this region in the functional regulation of mouse renal tumorigenesis. Further analysis of the complete nucleotide sequence of the $T s c 2-P k d 1$ region distinguishing the two AIR lines at the Rtm1 QTL region described in this study will allow the identification of the functional variant responsible for the high susceptibility to spontaneous and urethane-induced renal tumorigenesis of AIRmin mice and may provide insight into new modulating mechanisms of renal tumorigenesis in other species, including humans.

\section{Methods}

\section{Mice crosses}

AIRmax and AIRmin lines (formally designated IBut: AIRH and IBut:AIRL, respectively, at the Institute for Laboratory Animals Research, Washington, DC, USA) and their crosses were developed and maintained at the animal facilities of the Laboratory of Immunogenetics of the Butantan Institute. For genome-wide linkage analysis, pedigrees were obtained by intercrossing AIRmax with AIRmin mice (both from the $48^{\text {th }}$ generation of the selective bi-directional breeding), which resulted in the generation of 66 F1 (AIRmax x AIRmin) mice. These F1 mice were intercrossed to generate 693 (AIRmax x AIRmin)F2 mice. Animal procedures were approved by the Institutional Animal Care and Use Committee of Butantan Institute and all animals received humane care according to the criteria outlined in the "Guide for the Care and Use of Laboratory Animals" [32].

Renal tumor induction and inflammatory response assay To chemically induce tumors, mice pups received a subcutaneous injection of urethane $(300 \mathrm{mg} / \mathrm{kg}$ body weight) 7 days after birth. After 2 months, the same mice were tested for their acute inflammatory response by subcutaneous injection of $750 \mu \mathrm{l}$ of a sterile suspension of $67 \%$ Bio-Gel P-100 (Bio-Rad, Hercules, CA, USA) (53 mg dry weight $/ \mathrm{ml}$ ) in phosphate-buffered saline. Local exudates were harvested $24 \mathrm{~h}$ later: the total cell count (Ncell) was determined using Malassez hemocytometer chambers [6].

Mice were sacrificed 240 days after urethane treatment (i.e. at 35 weeks of age) in a $\mathrm{CO}_{2}$ chamber, and tumors in internal organs were scored macroscopically. Samples of normal and tumor-containing kidneys were collected for immunohistochemical analyses and RNA extraction.

As a negative control for the chemical induction of tumors, untreated parental AIRmax and AIRmin mice were sacrificed at 400 days (i.e. 57 weeks of age) and examined for the presence of spontaneous tumors.

\section{Immunohistochemistry}

Tumor-containing kidneys were fixed with formalin and embedded in paraffin. Sections $(3 \mu \mathrm{m})$ were rehydrated and antigens were retrieved with Tris-EDTA buffer $(\mathrm{pH}=9)$ using a PT Link instrument (Dako, Glostrup, Denmark). Immunohistochemical analysis was done using the EnVision FLEX kit (Dako). Briefly, after endogenous peroxidase blocking, slides were incubated in a humidified chamber for $30 \mathrm{~min}$ with polyclonal antisera to either alpha-methylacyl coenzyme A racemase or CD10 (Proteintech Group, Chicago, IL, USA) diluted 1:50. The signal was amplified using specific EnVision FLEX Rabbit Linker and colorimetric detection was completed with 3-3'-diaminobenzidine. Slides were counterstained with hematoxylin and mounted with Eukitt mounting medium (Bio-Optica, Milan, Italy).

\section{Analysis of gene expression by qRT-PCR}

Total RNA was extracted from RNAlater ${ }^{\mathrm{TM}}$ preserved kidney tumors and RNA integrity was determined in the Agilent 2100 bioanalyzer (Agilent, Waldbronn, Germany). Primers were designed with Primer-BLAST (http://www.ncbi.nlm.nih.gov/tools/primer-blast/), with the exception of $B 2 m$, which were obtained from PrimerBank (ID 144227219b3, http://pga.mgh.harvard. edu/primerbank/). The $5^{\prime}-3^{\prime}$ primer sequences were: $B 2 m$ (F CCCCACTGAGACTGATACATACG and $\mathrm{R}$ CGATCCCAGTAGACGGTCTTG); Vim (F TGGTACAA GTCCAAGTTTGC and R CTCCGGTACTCGTTTGACT) and Ribosomal protein S29 (Rps29, F TCTACTGGAGTCA CCCACGGAAGT and R TCAGTCGAATCCATTCAAGG TCGC). Reactions were run in a StepOnePlus ${ }^{\mathrm{Tm}}$ real-time detector using the Fast SYBR ${ }^{\bullet}$ Green Master Mix (Applied Biosystems, Foster City, CA). Relative gene expression was calculated by the $\Delta \Delta \mathrm{Ct}$ method [33] using pooled normal kidney mRNA from AIRmax mice as calibrator and Rps 29 as reference gene. 


\section{Genome-wide SNP genotyping}

Genomic DNA was extracted from tail tips using the E.Z.N. A. Tissue DNA Kit (Omega Bio-Tek, Norcross, GA, USA) and quantified by fluorimetry (Invitrogen, Carlsbad, CA, USA). SNPs were genotyped in each mouse of the pedigree with the BeadArray technology (Illumina, San Diego, CA, USA), using the Mouse MD Linkage Panel, which permits analysis of 1449 SNP loci; bead chips were read in an iScan system (Illumina), as described [34]. Genome maps are based on Genome assembly GRCm38, Ensembl release 71.

\section{Statistical analysis}

The search for QTLs was carried out with genome-wide linkage analysis between genotypes and phenotypes by interval mapping using GridQTL version 1.3.2. [35]. The significance thresholds of LOD scores for phenotypegenotype linkages were estimated by genome-wide permutation analysis. Odds ratios were calculated using logistic analysis. P-values were two-sided.

\section{Endnote}

ahttp://www.ensembl.org/biomart - Accessed May 9, 2013.

bhttp://www.ensembl.org/Mus_musculus/Transcript/ Summary?db=core;g=ENSMUSG00000002496;r=17:2459593724632629;t=ENSMUST00000097373 - Accessed on April 18, 2013.

chttp://www.ensembl.org/Mus_musculus/Gene/ Variation_Gene/Table?db=core;g=ENSMUSG00000002496; $\mathrm{r}=17: 24595937-24632629 ; \mathrm{t}=$ ENSMUST00000097373 Accessed on April 18, 2013.

\section{Abbreviations \\ AIR: Acute inflammatory response; AMACR: Alpha-methylacyl coenzyme A racemase; LOD: Logarithm of odds; QTL: Quantitative trait locus; Rtm1: Renal tumor modifier QTL 1; SNP: Single nucleotide polymorphism. \\ Competing interests \\ The authors have no interest, arrangement, or affiliation that could be perceived as a conflict of interest in the context of this manuscript.}

\section{Authors' contributions}

JRJ and AG carried out the SNP array analysis and drafted and finalized the manuscript. AB, WC, MDF, OGR and NS were involved in many aspects of the study, including animal crossing, treatment, autopsy, and phenotype analysis. $\mathrm{ABe}$ and MC provided histopathological analysis, TAD performed the statistical analysis and revised the manuscript, and OCMI designed and supervised the study and revised the manuscript. All authors read and approved the final manuscript.

\section{Acknowledgements}

This work was supported in part by funds from São Paulo Research Foundation (FAPESP, Proc.N²011/21129-6) and the Brazilian National Research Council (CNPq). Valerie Matarese provided scientific editing.

\section{Author details}

${ }^{1}$ Laboratory of Immunogenetics, Instituto Butantan, Avenida Dr. Vital Brazil, 1500, 05503-900 São Paulo, Brazil. ${ }^{2}$ Department of Predictive and Preventive Medicine, Fondazione IRCCS Istituto Nazionale dei Tumori, Milan, Italy. ${ }^{3}$ Department of Pathology, Fondazione IRCCS Istituto Nazionale dei Tumori, Milan, Italy.
Received: 21 June 2013 Accepted: 11 October 2013

Published: 22 October 2013

\section{References}

1. Linehan WM, Srinivasan R, Schmidt LS: The genetic basis of kidney cancer: a metabolic disease. Nat Rev Urol 2010, 7:277-285.

2. Chow WH, Gridley G, Fraumeni JF Jr, Jarvholm B: Obesity, hypertension, and the risk of kidney cancer in men. N Engl J Med 2000, 343:1305-1311.

3. Liu $H$, Sundquist $J$, Hemminki $K$ : Familial renal cell carcinoma from the Swedish family-cancer database. Eur Urol 2011, 60:987-993.

4. Wu X, Scelo G, Purdue MP, Rothman N, Johansson M, Ye Y, Wang Z, Zelenika D, Moore LE, Wood CG, Prokhortchouk E, Gaborieau V, Jacobs KB, Chow WH, Toro JR, Zaridze D, Lin J, Lubinski J, Trubicka J, Szeszenia-Dabrowska N, Lissowska J, Rudnai P, Fabianova E, Mates D, Jinga V, Bencko V, Slamova A, Holcatova I, Navratilova M, Janout V, et al: A genome-wide association study identifies a novel susceptibility locus for renal cell carcinoma on 12p11.23. Hum Mol Genet 2012, 21:456-462.

5. Purdue MP, Johansson M, Zelenika D, Toro JR, Scelo G, Moore LE, Prokhortchouk E, Wu X, Kiemeney LA, Gaborieau V, Jacobs KB, Chow WH, Zaridze D, Matveev V, Lubinski J, Trubicka J, Szeszenia-Dabrowska N, Lissowska J, Rudnai P, Fabianova E, Bucur A, Bencko V, Foretova L, Janout V, Boffetta P, Colt JS, Davis FG, Schwartz KL, Banks RE, Selby PJ, et al: Genome-wide association study of renal cell carcinoma identifies two susceptibility loci on 2p21 and 11q13.3. Nat Genet 2011, 43:60-65.

6. Ibanez OM, Stiffel C, Ribeiro OG, Cabrera WK, Massa S, De Franco M, Sant'anna OA, Decreusefond C, Mouton D, Siqueira M, Biozzi G: Genetics of nonspecific immunity: I. Bidirectional selective breeding of lines of mice endowed with maximal or minimal inflammatory responsiveness. Eur $\mathrm{J}$ Immunol 1992, 22:2555-2563.

7. Ribeiro OG, Maria DA, Adriouch S, Pechberty S, Cabrera WH, Morisset J, Ibanez OM, Seman M: Convergent alteration of granulopoiesis, chemotactic activity, and neutrophil apoptosis during mouse selection for high acute inflammatory response. J Leukoc Biol 2003, 74:497-506.

8. Biozzi G, Ribeiro OG, Saran A, Araujo ML, Maria DA, De Franco M, Cabrera WK, Sant'anna OA, Massa S, Covelli V, Mouton D, Neveu T, Siqueira M, Ibanez OM: Effect of genetic modification of acute inflammatory responsiveness on tumorigenesis in the mouse. Carcinogenesis 1998 19:337-346

9. Maria DA, Manenti G, Galbiati F, Ribeiro OG, Cabrera WH, Barrera RG, Pettinicchio A, De Franco M, Starobinas N, Siqueira M, Dragani TA, Ibanez OM: Pulmonary adenoma susceptibility 1 (Pas1) locus affects inflammatory response. Oncogene 2003, 22:426-432.

10. Di Pace RF, Massa S, Ribeiro OG, Cabrera WH, De Franco M, Starobinas N, Seman M, Ibanez OC: Inverse genetic predisposition to colon versus lung carcinogenesis in mouse lines selected based on acute inflammatory responsiveness. Carcinogenesis 2006, 27:1517-1525.

11. Hoffler U, El Masri HA, Ghanayem BI: Cytochrome P450 2E1 (CYP2E1) is the principal enzyme responsible for urethane metabolism: comparative studies using CYP2E1-null and wild-type mice. J Pharmacol Exp Ther 2003, 305:557-564.

12. Qayyum T, McArdle PA, Lamb GW, Going JJ, Orange C, Seywright M, Horgan PG, Oades G, Aitchison MA, Edwards J: Prospective study of the role of inflammation in renal cancer. Urol Int 2012, 88:277-281.

13. Galvan A, Vorraro F, Cabrera WH, Ribeiro OG, Pazzaglia S, Mancuso M, Zolin A, Milani S, Saran A, Ibanez OM, Dragani TA: Genetic heterogeneity of inflammatory response and skin tumorigenesis in phenotypically selected mouse lines. Cancer Lett 2010, 295:54-58.

14. Manenti G, Dragani TA: Pas1 Haplotype-dependent genetic predisposition to lung tumorigenesis in rodents: a meta-analysis. Carcinogenesis 2005, 26:875-882

15. Tretiakova MS, Sahoo S, Takahashi M, Turkyilmaz M, Vogelzang NJ, Lin F, Krausz T, Teh BT, Yang XJ: Expression of alpha-methylacyl-CoA racemase in papillary renal cell carcinoma. Am J Surg Pathol 2004, 28:69-76.

16. Maguer-Satta V, Besancon R, Bachelard-Cascales E: Concise review: neutra endopeptidase (CD10): a multifaceted environment actor in stem cells, physiological mechanisms, and cancer. Stem Cells 2011, 29:389-396.

17. Higgins JP, Shinghal R, Gill H, Reese JH, Terris M, Cohen RJ, Fero M, Pollack JR, van de Rijn M, Brooks JD: Gene expression patterns in renal cell carcinoma assessed by complementary DNA microarray. Am J Pathol 2003, 162:925-932. 
18. Young AN, de Oliveira Salles PG, Lim SD, Cohen C, Petros JA, Marshall FF, Neish AS, Amin MB: Beta defensin-1, parvalbumin, and vimentin: a panel of diagnostic immunohistochemical markers for renal tumors derived from gene expression profiling studies using CDNA microarrays. Am J Surg Pathol 2003, 27:199-205.

19. Nomura T, Huang WC, Seo S, Zhau HE, Mimata H, Chung LW: Targeting beta2-microglobulin mediated signaling as a novel therapeutic approach for human renal cell carcinoma. J Urol 2007, 178:292-300.

20. Dragani TA, Sozzi G, Della Porta G: Spontaneous and urethan-induced tumor incidence in B6C3F1 versus B6CF1 mice. Tumori 1984, 70:485-490.

21. Haseman JK, Huff JE, Rao GN, Arnold JE, Boorman GA, McConnell EE: Neoplasms observed in untreated and corn oil gavage control groups of F344/N rats and (C57BL/6N X C3H/HeN)F1 (B6C3F1) mice. J Natl Cancer Inst 1985, 75:975-984.

22. Sass $B$, Peters RL, Kelloff GJ: Differences in tumor incidence in two substrains of claude BALB/C (BALB/cfCd) mice, emphasizing renal, mammary, pancreatic, and synovial tumors. Lab Anim Sci 1976, 26:736-741.

23. Garcia $M$, Wellinger $R$, Vessaz A, Diggelmann $H$ : A new site of integration for mouse mammary tumor virus proviral DNA common to $\mathrm{BALB} / \mathrm{Cf}(\mathrm{C} 3 \mathrm{H})$ mammary and kidney adenocarcinomas. EMBO J 1986, 5:127-134.

24. Yeung RS, Xiao G, Jin F, Lee W, Testa JR, Knudson AG: Predisposition to renal carcinoma in the eker rat is determined by germ-line mutation of the tuberous sclerosis 2 (TSC2) gene. Proc Natl Acad Sci USA 1994, 91:11413-11416.

25. Kobayashi T, Hirayama Y, Kobayashi E, Kubo Y, Hino O: A germline insertion in the tuberous sclerosis (Tsc2) gene gives rise to the eker rat model of dominantly inherited cancer. Nature Genet 1995, 9:70-74.

26. Xiao GH, Jin F, Yeung RS: Germ-line Tsc2 mutation in a dominantly inherited cancer model defines a novel family of rat intracisternal-a particle elements. Oncogene 1995, 11:81-87.

27. Dere R, Wilson PD, Sandford RN, Walker CL: Carboxy terminal tail of polycystin-1 regulates localization of TSC2 to repress mTOR. PLoS One 2010, 5:e9239.

28. Onda H, Lueck A, Marks PW, Warren HB, Kwiatkowski DJ: Tsc2(+/-) Mice develop tumors in multiple sites that express gelsolin and are influenced by genetic background. J Clin Invest 1999, 104:687-695.

29. Audrezet MP, Cornec-Le Gall E, Chen JM, Redon S, Quere I, Creff J, Benech C, Maestri S, Le Meur Y, Ferec C: Autosomal dominant polycystic kidney disease: comprehensive mutation analysis of PKD1 and PKD2 in 700 unrelated patients. Hum Mutat 2012, 33:1239-1250.

30. Menezes LF, Zhou F, Patterson AD, Piontek KB, Krausz KW, Gonzalez FJ, Germino GG: Network analysis of a Pkd1-mouse model of autosomal dominant polycystic kidney disease identifies HNF4alpha as a disease modifier. PLoS Genet 2012, 8:e1003053.

31. Zhang K, Ye C, Zhou Q, Zheng R, Lv X, Chen Y, Hu Z, Guo H, Zhang Z, Wang $Y$, Tan R, Liu Y: PKD1 Inhibits cancer cells migration and invasion via Wnt signaling pathway in vitro. Cell Biochem Funct 2007, 25:767-774.

32. NRC (National Research Council), Institute of Laboratory Animal Resources: Guide for the care and use of laboratory animals. 8th edition. Washington, D. C: National Academy Press; 2011

33. Livak KJ, Schmittgen TD: Analysis of relative gene expression data using real-time quantitative PCR and the 2(-delta delta $C(T)$ ) method. Methods 2001, 25:402-408

34. Vorraro F, Galvan A, Cabrera WH, Carneiro PS, Ribeiro OG, De Franco M, Starobinas N, Jensen JR, Seman M, Dragani TA, Ibanez OC: Genetic control of IL-1 beta production and inflammatory response by the mouse Irm1 locus. J Immunol 2010, 185:1616-1621.

35. Seaton G, Haley CS, Knott SA, Kearsey M, Visscher PM: QTL express: mapping quantitative trait loci in simple and complex pedigrees. Bioinformatics 2002, 18:339-340.

doi:10.1186/1471-2164-14-724

Cite this article as: Jensen et al:: Genetic control of renal tumorigenesis by the mouse Rtm1 locus. BMC Genomics 2013 14:724

\section{Submit your next manuscript to BioMed Central and take full advantage of:}

- Convenient online submission

- Thorough peer review

- No space constraints or color figure charges

- Immediate publication on acceptance

- Inclusion in PubMed, CAS, Scopus and Google Scholar

- Research which is freely available for redistribution

Submit your manuscript at www.biomedcentral.com/submit
Ciomed Central 